\title{
LA CONSTRUCCIÓN DE LA IDENTIDAD DOCENTE EN EDUCACIÓN INFANTIL
}

\author{
Carmen Sarceda Gorgoso \\ Universidad de Santiago de Compostela
}

\section{RESUMEN}

Este trabajo es fruto de un proceso de investigación más amplio orientado a comprender como se crea la identidad docente en Educación Infantil y la influencia que ejercen la vida privada, la laboral y las reformas educativas en su construcción. Dada la amplitud del proyecto, en este documento se abordan dos objetivos específicos: dar a conocer la historia de vida de una docente de Educación Infantil, e identificar los elementos más significativos en la creación de su identidad docente. A través del método biográfico-narrativo, se ofrece la historia de vida de Catuxa, profesora jubilada de Educación Infantil. Los resultados nos llevan a comprender los conflictos, dificultades, disyuntivas y circunstancias a las que ha tenido que enfrentarse durante una carrera docente de casi 40 años.

\section{PALABRAS CLAVE}

Profesor - educación de la primera infancia - investigación pedagógica desarrollo profesional - biografías.

\begin{abstract}
This work is the result of extensive research aimed to understand how to create a teaching identity in early childhood education, and how this influences the teachers private life and work life as educational reform is introduced. Given the scope of the project, in this document, two specific objectives are addressed: to publicise the life history of a teacher of early childhood education, and identify the most significant elements in the creation of his/her teaching identity. The life history of a retired infant teacher called Catuxa is used throughout this report using the narrative-biographic method. The results help us to better understand the conflicts, difficulties, dilemmas and circumstances that the teacher had to face during a teaching career near 40 years.
\end{abstract}

\section{KEY WORDS}

Teacher - early childhood education - educational research - professional identity - biographies. 


\section{INTRODUCCIÓN}

La construcción de la identidad profesional se constituye en un proceso que se desarrolla a lo largo de toda la vida del docente, incluyendo tanto las vivencias previas al ejercicio profesional como las primeras experiencias como alumnos (Zeichner y Gore, 1990), así como aquellas otras surgidas en el devenir de su actividad como maestro. En este proceso se defiende el papel del docente como protagonista de su proceso de desarrollo profesional, poniéndose el acento en la manera en que los profesores y profesoras adoptan nuevos roles que los convierten en agentes activos del proceso al tiempo que van conformando su identidad profesional en el marco de un modelo reflexivo (Schön, 1998), en el que su actividad retrospectiva-introspectiva les permite establecer conexiones entre las vivencias profesionales y personales, construyendo su identidad en el marco de una lógica vinculada al espacio sociocultural en el que se imbrica (Calderón, 2014). Por ello se podría decir que la identidad docente es una construcción individual referida a la historia del docente y a sus características sociales, pero también una construcción colectiva vinculada al contexto en el cual el docente trabaja (Valliant, 2007) y a todo lo que le rodea, entendiendo, tal y como afirma Matus (2013), que es un proceso social, dinámico y continuo, que vincula la acción individual asociada a las historias de vida, con la acción colectiva que se desarrolla, al mismo tiempo que la dota de sentido, reinterpretando las propias creencias, experiencias y valores (Correa, Fernández, Gutiérrez-Cabello, Losada y Ochoa-Aizpurua, 2015).

En esta línea se sitúa Goodson (2004) al considerar que en la construcción de la identidad docente los modelos vivenciados tienen una gran influencia, especialmente aquellos que rememoran recuerdos positivos. Se afirma que tiene múltiples dimensiones que conjugan elementos racionales y no racionales (Bolívar, 2007, Day, 2007), lo que promueve que haya sido estudiada desde diversas perspectivas teóricas que pretenden profundizar en sus diferentes caras.

\subsection{La investigación sobre el tema}

Hace casi 15 años, Beijaard, Meijer y Verloop (2004) sobre la base de una exhaustiva revisión de investigaciones acerca de la identidad profesional, concluían que la investigación sobre la construcción de la identidad docente carecía de estudios centrados en la dimensión contextual del proceso.

Sin embargo, en los últimos años emergen con fuerza enfoques de investigación que ponen el peso en el modo en cómo surge el conocimiento sedimentado a lo largo de los procesos personales en contacto con la escuela (Cortés, Leite y Rivas, 2014). Así, la formación del profesorado y la construcción de su identidad docente es estudiada desde una dimensión cualitativa y holística que parte del reconocimiento del carácter contextual del conocimiento (Bolivar, 2014; Bretones, Solé, Alberich y Ros, 2014; Caballero y Bolívar, 2015; Correa, 2014; Correa y Aberasturi, 2014; Gutiérrez, 2014; Hernández y Aberasturi, 2014; Macuch y Leite, 2014; Neiva, Lopes y Pereira, 2014; Serret-Segura, Martí-Puig y Corbatón, 2016; Thomas y Soares, 2015, entre otros).

En estos trabajos, enmarcados en una perspectiva interpretativa, se pone de manifiesto la importancia de investigar las identidades docentes, poniendo el foco de atención en la realidad personal y el proceso biográfico. En este sentido, como afirman Monereo y Domínguez (2015) "la identidad ha dejado de 
considerarse como cualidad única, inmutable, fija, y relativa a la personalidad de un individuo, para pasar a conceptualizarse como múltiple, discontinua y socialmente sensible" (p.86).

Tomando como referencia estas aportaciones, concebimos la identidad profesional como un proyecto nunca finalizado, cambiante, situacional y relacional (Correa et al., 2015) que describe el modo en que el profesorado encuentra sentido a su práctica profesional. En este sentido, abordamos nuestro objeto de estudio desde una perspectiva holística que nos permite atender a las diferentes dimensiones que conforman al profesorado como persona, profesional y docente (Day, Stobart, Sammons, Kington, Gu, Semees y Mujtaba, 2006) y que conlleva una constante interpretación y reinterpretación de la identidad a partir de las experiencias vivenciadas (Beijaard et al. 2004).

Desde esta premisa, en este trabajo se presenta la historia de vida de Catuxa, profesora jubilada de Educación Infantil sobre la base de dos objetivos: dar a conocer la historia de vida de una docente de Educación Infantil, e identificar los elementos más significativos en la creación de su identidad docente. Su voz nos permite comprender los dilemas y contradicciones a los que se ha enfrentado a lo largo de su vida profesional y personal, y cómo ha ido construyendo su identidad docente a través de los años y las vivencias experimentadas.

\section{METODOLOGÍA}

\subsection{Método: La historia de vida.}

La historia de vida es una narración, un relato o una exposición de acontecimientos, ya sean reales o ficticios. Esto permite decir que una historia de vida es un relato con los sucesos que una persona vivió a lo largo de su existencia. En este sentido, las historias de vida en educación permiten "narrar vínculos, prácticas, encuentros y desecuentros, espacios de formación, espacios de conciliación y disonancia, narrar escenarios, vivencias, luces y sombras" (Piqué y Forés, 2015, p. 248). Este relato nunca será exhaustivo ya que resulta imposible reseñar cada acontecimiento que ocurrió en la vida de un sujeto desde el nacimiento hasta el presente o su muerte.

Las historias de vida son una forma de producir conocimiento y comprensión sobre la sociedad y la cultura de la que participan las personas. Las historias de vida nos cautivan y nos incumben porque nos interesamos por las vidas de las personas y lo hacemos con el objetivo de intentar comprender cuáles son las vivencias subjetivas que tienen de su experiencia vital, a la vez que ponemos en relación estas vidas particulares con las situaciones socioculturales e interpersonales en las que están inmersas (Bretones et al., 2014, pp.71-72).

Con la aparición del método biográfico en las ciencias sociales, allá por los años 20, comenzó a utilizarse el término life history, para describir tanto la narrativa vital de una persona, recogida por un investigador, como la versión final elaborada a partir de dicha narrativa. Posteriormente se introduce el término life story para "referirse exclusivamente a la narración biográfica de un sujeto, tal como lo contó, frente a life history que comprendería también cualquier otro tipo de información adicional" (Porto, 2003, p.21). 
Otra manera de ver la diferencia entre "historia de vida" (life history) y "relato de vida" (life story) es como bien apunta Pujadas (2002). El segundo término es la historia de una vida contada tal cual por la persona en función de lo vivido sin nada más, en cambio la primera (life history) se refiere al "estudio de caso de una persona, comprendiendo no sólo su relato de vida sino cualquier otro tipo de información o documentación adicional, que permita la reconstrucción de dicha biografía de la forma más exhaustiva y objetiva posible" (Pujadas, 2002, p.13). A la hora de crear una historia de vida se hace vital el llevar a cabo una serie de pasos necesarios para conseguir que el resultado sea el esperado.

Además se hace igualmente imprescindible, antes de ponerse a redactar, el establecer un orden cronológico de todos los documentos que se poseen sobre el individuo pues, de esta manera, es como se podrá tener clara la sucesión de los acontecimientos que fueron fundamentales en la vida de aquel, de tal modo que en esta historia se cuenta la trayectoria de vida personal y profesional, con las múltiples experiencias que, en sus tiempos y contratiempos, han jalonado y configurado el itinerario de vida (Pineau, 2004). En este sentido, Fernández (1995) afirma que:

Las historias personales de la experiencia proporcionan el marco biográfico que hace inteligible el desarrollo profesional de los docentes. La aproximación narrativa que suponen las historias personales de la experiencia es consustancial a la indagación biográfica. Es decir, no sólo es que la vida en la enseñanza sea una historia narrada, sino que la propia enseñanza es una historia narrada. (p.157).

En este relato lo que se busca es dar sentido a lo vivido, estableciendo una conexión coherente entre los diversos acontecimientos y experiencias de la vida que su protagonista considera relevantes. Finalmente, señalar que la historia de vida representa una metodología de investigación cualitativa que forma parte "del movimiento general de crítica al positivismo y a la investigación basada en datos empíricos cuya crisis ha favorecido el desarrollo, además de las historias de vida, de otras metodologías de tipo cualitativo" (Bilbao, Pérez y Ezkurdia 2014, p.87).

\subsection{Objetivos}

El objetivo general de la investigación en la que se enmarca este trabajo, se orienta a comprender como se crea la identidad docente en Educación Infantil, y la influencia que ejercen la vida privada, la laboral y las reformas educativas en la creación de la misma.

Dadas las limitaciones de espacio, en este documento se abordan los siguientes objetivos específicos:

- Dar a conocer la historia de vida de una docente de Educación Infantil

- Identificar los elementos más significativos en la creación de su identidad docente 


\subsection{Selección del caso}

A la hora de seleccionar el caso, se establecieron dos criterios básicos que debían cumplirse para dotar de rigor científico y académico al estudio:

- Que hubiera vivido como docente diferentes reformas educativas en Educación Infantil, puesto que esto dotaría de mayor contenido a la historia de vida.

- Que se comprometiera a colaborar y aportar documentación necesaria.

Una vez identificado el caso y con la finalidad de comprobar si nuestra potencial protagonista cumplía estos requisitos, se hace una primera toma de contacto vía telefónica, en la cual se le explica el tipo de investigación que se va a llevar a cabo, cuáles son sus objetivos y cuál el papel que desempeñaría en el mismo. La respuesta fue afirmativa por parte de ella y tras la constatación del cumplimiento de las condiciones establecidas, se ratifica la colaboración, aunque solicita expresamente el anonimato. Llegado a este punto y de mutuo acuerdo se busca un nombre ficticio, pactado por ambas partes (Catuxa).

\subsection{Instrumento}

Para la obtención de la información, se utiliza como instrumento para la recogida de información la entrevista semiestructurada (Cohen y Manion, 1990; Cook y Reichardt, 1986), que permitió determinar de antemano la información relevante a conseguir. Se realizaron preguntas abiertas, establecidas tomando como referencia los grupos de influencia propuestos por Day et al. (2006) y Day (2011), que dieron oportunidad a recibir más matices de la respuesta, lo que permitió ir entrelazando temas, exigiendo al mismo tiempo, una gran atención por parte de la investigadora para poder encauzar y estirar los temas, desde una actitud de escucha. De la revisión de la literatura sobre el tema y de investigaciones precedentes, se diseña un guión de entrevista según las pautas propuestas por King y Horrocks (2010): incluir en el mismo grupo las preguntas vinculadas a un mismo tema, y secuenciar éstas de manera que asegure la exhaustividad de las respuestas al tiempo que minimice la posibilidad de reiteración, fatiga y/o cansancio por parte de entrevistado y entrevistador.

El instrumento definitivo fue sometido a validación teórica por tres expertos en el campo de la Formación del Profesorado y de la Educación Infantil, quedando estructurado en cinco grandes dimensiones (Tabla 1): infancia y adolescencia, toma de decisiones, paso por la universidad, los años de docencia $y$, los años de madurez. 


\begin{tabular}{l|l}
\hline DIMENSIONES & PREGUNTAS \\
\hline &
\end{tabular}

Para ponernos en escena Catuxa, ¿te importaría decirme tu edad, más o menos para situarnos en el momento y de dónde eres, es decir, dónde viviste tus primeros años de vida?

Infancia, adolescencia

¿Con quién vivías por aquel entonces, cuantas personas vivían en tu casa? ¿qué parentesco tenías con ellos?

En aquel momento, durante tus primeros años académicos, ¿Cómo era la educación? Con respecto a tu escolarización, ¿me podrías contar algo más de cómo fue tú paso por el colegio? Es decir, ¿Dónde estudiaste, cuantos años, cómo era tu escuela...? ¿Qué tipo de relación teníais con el maestro/a? ¿Qué relación teníais los compañeros? ¿Había algún tipo de relación padres-profesor?

¿Te gustaría destacar algo de tu infancia/adolescencia que no me hayas contando ya y que consideres que te ha marcado de forma especial con respecto a tu futuro?

Toma de decisiones

En lo que respecta a la decisión de estudiar Magisterio, ¿cuándo sucedió? ¿Cuándo o cómo te diste cuenta de que querías ser maestra?

¿La decisión de estudiar fue una decisión tuya o tuviste influencia de tu familia? En función de la respuesta... ¿Tuviste apoyo de tu familia al llevar a cabo esta decisión?

Tomada ya una de las decisiones más importantes de tu vida, ¿En qué año comenzaste a estudiarla?

En ese momento de comenzar a estudiar, ¿En qué condiciones se encontraba magisterio dentro de las enseñanzas universitarias? ¿Qué podrías destacar con relación a alguna característica especialmente significativa para tí?

Paso por la A nivel del profesorado ¿Tenías algún trato cordial con ellos o simplemente eran meros Universidad $\quad$ transmisores de conocimientos? ¿Qué tipo de sensaciones os transmitían?

Ese tipo de relación que tenías con los profesores ¿Crees que te marcó a la hora de tu futura labor como maestra?

Cuando estabas estudiando ¿Te daba la sensación de que esa formación y esos profesores estaban politizados?

Todo esto que recuerdas, lo estudiado y lo aprendido... ¿Lo aplicaste después en el aula?

Comencemos entonces a hablar ahora de tu vida como docente y de todo lo que pasó en ella, tus sentimientos, emociones, contradicciones...

Prácticamente todo tu tiempo en el colegio lo pasaste con niños, por ello te pregunto ¿Socialmente, cómo crees que se veía a las maestras? No me refiero sólo a nivel económico, sino también por el trato recibido por los profesores y resto de la comunidad ¿Notaste en algún momento algún tipo de aislamiento, al tratar sólo con niños durante tu jornada?

¿Qué tipo de relación tenías con tus compañeros? ¿Personal, profesional, ambas, ninguna...?

Supongo que en tu memoria tendrás miles de recuerdos de tu alumnado. Cuéntame por favor, el mejor que tengas y el peor, que influyesen tu vida como docente.

Los años de docencia Tener tantas experiencias con niños, a mi me lleva a pensar en la estabilidad emocional tanto tuya como de ellos, como crees que influye en ellos? Es decir, ¿Crees que les afecta a la hora de su aprendizaje? ¿Crees que el contexto también puede influir en esa estabilidad?

Cuando empezaste la carrera, retomando un poco también tus inicios, ¿Te hacías a la idea de que trabajar con niños te iba a afectar a nivel emocional y personal?

Viendo que tu influyes tanto en los niños, y también ellos en ti ¿Podrías decirme si tu comportamiento, lo que fuiste vivenciando, hizo que sufrieras muchos cambios como docente?

¿Te sentiste en algún momento poco valorada? Si la respuesta es afirmativa ¿Esto conllevó cambios a nivel personal, qué cambios notaste en tus intereses o actitudes?

Todos tus cambios a nivel profesional y personal ¿Crees que pudieron afectar a tu lugar de trabajo (el cole)?

Que no se nos olvide tampoco que eres una mujer, y si aún hoy en día no hay igualdad, menos me quiero imaginar hace años... ¿En algún momento de tu vida laboral te sentiste inferior a tus compañeros varones, por ser mujer o por el tipo de carrera que escogiste?

Aparte de lo vivido día a día, lo compartido con el alumnado y el resto de la comunidad, hay otros factores que influyen mucho en una persona, como son el cambio de leyes, la introducción de nuevas tecnologías, de metodologías diferentes...por eso pregunto ahora sobre esa temática.

Los años de madurez

Hubo muchos cambios de leyes durante tu vida como profesora; la primera con la que trabajaste fue la LGE pero quizá la que más tiempo te afectó fue la LOGSE. ¿Cómo vivencias este cambio de ley? ¿Los cambios afectan a tu forma de dar clase? ¿Notas alguna diferencia en el alumnado que estudió con una ley y con otra?

También en esta época hay un cambio de metodologías, como la introducción de los ordenadores en el aula ¿Esto a ti te afecta en tu forma de enseñar a los niños? 


\begin{tabular}{l|l}
\hline & ¿Ves difícil compaginar una enseñanza tradicional como la que empezaste con esta \\
nueva sociedad que se plantea de nuevas tecnologías? & A nivel de tú formación, ya que todo esto fue cambiando a pasos agigantados \\
& ¿Necesitaste algún tipo de formación extra para avanzar en tu profesión? \\
Y ese tipo de formación extra también abarcaba a nivel emocional? ¿Crees que tuviste \\
formación suficiente? \\
Por último con respecto a todos estos cambios, como todo cambia y todo evoluciona, \\
¿Qué retos crees que debe asumir la educación del siglo XXI? \\
Finalizando esta entrevista, te voy a hacer la que considero quizá sea la pregunta más \\
importante ¿Crees que la decisión de estudiar esta carrera fue la más acertada? \\
¿Cambiarías si volvieras atrás?
\end{tabular}

Tabla 1. Dimensiones y preguntas de la entrevista

\subsection{Procedimiento.}

Se comenzó pactando un día, hora y lugar para proceder con la primera entrevista. Esta primera entrevista resultó ser la más larga, y en ella se hizo un repaso cronológico de la biografía de la entrevistada, y en la que iba mostrando documentos acreditativos, tales como su título universitario. Finalizada dicha entrevista, se procedió a la transcripción de la entrevista y a su análisis, para poder focalizar y abordar en la siguiente entrevista aspectos dudosos o de especial interés, poniendo una especial atención en la reflexión, de manera que se pudiera dotar a la narrativa de un carácter formativo (Thomas y Soares, 2015).

La segunda entrevista comienza con una revisión en común por ambas partes de la entrevista anterior, para enmendar los posibles errores cometidos en la trascripción o clarificar determinados aspectos.

Modificada la trascripción inicial y ampliada, se lleva a cabo una última reunión, en la que se le presentó a la entrevistada la trascripción final, a la que ésta da el aprobado definitivo. Estas entrevistas son realizadas y grabadas en audio en la vivienda de la entrevistada (por petición de ella) entre marzo y mayo de 2016.

\subsection{Análisis de datos.}

El análisis de los datos se lleva a cabo desde el paradigma cualitativo, dentro de un marco interpretativo (Popkewitz, 1980), utilizando una metodología de análisis de contenido que nos permite aproximarnos a la información con sistematicidad y objetividad (Cohen y Manion, 1990; Cook y Reichardt, 1986). Se empleó como unidad de análisis los enunciados de las respuestas ofrecidas por la entrevistada (siempre y cuando poseyeran significado), por lo que se caracterizaría como una unidad de base gramatical.

El resultado final es el que se presenta a continuación, la historia de vida de Catuxa. Esta se presenta como un texto "en forma de notas explicativas al discurso" (Pujadas, 2002, p. 80), y dando entrada a textos de otros autores que dialogan con el relato (Creus, 2010).

\section{RESULTADOS}

En este apartado se presenta la voz de Catuxa. Con el objetivo de clarificar y facilitar la comprensión de lo que se expone, el discurso se organiza en 5 dimensiones que siguen la estructura del guión de la entrevista. 


\subsection{Infancia y adolescencia.}

Catuxa comienza su vida hace poco más de setenta y tres años (1943), en Barcelona (España), donde vivió poco tiempo ya que pronto se mudó con su familia para la provincia de Pontevedra, ciudad en la que pasó sus primeros 17 años de vida. Su familia está compuesta por sus padres, sus cuatro hermanos y ella, siendo el padre el que sustenta a la familia gracias a su cargo militar. En este momento, recién llegados a Pontevedra, comienza a estudiar en una escuela unitaria y a vivir en los pabellones militares. Así evoca sus experiencias escolares en aquella época:

[...] Mi primera clase fue en una escuela unitaria en la que sólo estábamos chicas. Tuvimos la gran suerte de que la profe era muy buena y cariñosa, cualidad que deberían de tener todos los profesores. [...]

La figura de la maestra se constituye en un referente para Catuxa que podría haber tenido repercusión para su futuro, puesto que tal y como menciona Sánchez (2003), es posible que "esta esencia vocacional se haya ido forjando, en algunos casos, en las edades más tempranas, al sentirse entusiasmado por los más pequeños, por la admiración hacia su maestro y por representar su mismo papel" (p. 206).

A la edad de diez años ingresa en el Instituto, todavía segregado por sexos. En este centro estudia hasta 4ํ curso y realiza la tan temida reválida, consiguiendo aprobarla y continuar con el bachillerato. De esta época, recuerda especialmente la relación con su maestro y compañeros, encontrando diferencias entre los distintos niveles:

[...] El tipo de relación que se tenía con el maestro era de trato cordial, al igual que con los compañeros, aunque si bien es cierto que el cambio de la escuela unitaria al instituto fue muy grande, porque las preocupaciones de los maestros eran diferentes. [...]

A partir de este momento no continúa con sus estudios, sino que deja el hogar familiar para ingresar en un internado. Pero esta es una etapa sobre la que Catuxa no parece querer profundizar, y que deja a la libre imaginación de la entrevistadora lo que sucede entre 1960 y 1970 durante el período que está internada.

Unos cuantos años después, aproximadamente en 1970, comenzó a dar clases en Palencia (no deja muy claro cómo llega hasta aquí). Esto le dejaría una huella especial con respecto a su futuro, ya que fue el primer contacto que tuvo con la profesión y marcaría el resto de su carrera laboral. El no poseer ninguna titulación específica para el ejercicio docente puede parecer sorprendente a día de hoy, pero como señala nuestra protagonista:

[...] En aquella época no te exigían ninguna titulación, simplemente que tuvieras $4^{\circ}$ curso y yo era exactamente lo que tenía, aparte de aprobar el bachillerato. [...]

Oficialmente ella no estaba contratada por el estado, pero daba clases en un colegio público, es decir, que tenía que fingir que era otra persona, porque impartía docencia con el título de una profesora que no era ella. Como recuerda:

[...] Si venía una inspección yo tenía que decir que me llamaba Consuelo. Recuerdo una vez en la que me preguntaron cuál era mi 
nombre y mis compañeras me decían por detrás: -di que eres Consuelo, te llamas Consuelo-. [...]

Sus clases eran exclusivamente de niñas y estaban abarrotadas. Cuenta que llegó a tener sesenta y dos alumnas en una misma aula:

[...] El aula estaba llena de niñas, hoy en día te pueden parecer muchísimas, una clase de locos, pero en aquel momento era todo mucho más fácil. [...]

Todo esto le hizo pensar que aunque cualquiera podía dar clase en un aula sin titulación, ella nunca se sentiría una auténtica profesional en esas condiciones. Este pensamiento enlaza con lo que García (1988) denuncia con respecto a la profesión docente y a su consideración en la época: "mientras que cualquier persona instruida crea poder convertirse automáticamente en enseñante, la profesión docente se encontrará en situación de inferioridad social respecto a otras profesiones" (p.266).

\subsection{Toma de decisiones.}

Después de haber estado cuatro o cinco años en Palencia dando clase, Catuxa tenía claro que quería ser maestra. Esta decisión se vincula con lo que Sánchez (2003) señala con respecto a la "diversidad de elementos que rodean la elección del magisterio, (...), no se trata de una circunstancia baladí, ya que de una buena o mala decisión puede depender todo el proceso de desarrollo personal y profesional de una persona" (p. 205).

Fue una decisión personal que tomó exclusivamente ella, aunque contó con total apoyo familiar, en especial de su padre:

[...] Mi padre estaba muy orgulloso de mí, pensaba que era una alegría tener una hija con una carrera universitaria. Es más, por mi culpa, mi hermana tuvo que estudiar también, aunque ella no quisiera. [...]

Como afirma Sánchez (2003, p. 2014) "la familia tiene entre otras funciones, la de colaborar y favorecer el proceso de toma de decisiones", y esto es exactamente lo que le pasó a Catuxa, ya que su familia favoreció y colaboró en este proceso.

Catuxa tuvo que cursar un año previo a entrar en la universidad, puesto que como señalan Román y Cano (2008):

En 1971 se elaboró un nuevo Plan de Estudios. Los estudios de Magisterio alcanzaban de nuevo la categoría de "carrera universitaria" (perdida en 1939), aunque de ciclo corto (tres años de duración), para la que como requisito de acceso, los estudiantes deberían haber finalizado el Bachiller Superior y completado con éxito el Curso de Orientación Universitaria (COU). No obstante, no se necesitaba haber pasado por la prueba de Selectividad (p. 91).

Tomada ya la decisión más importante de su vida comenzó a estudiar Magisterio en Orense en el curso 1973-1974 (tenía ya treinta años) por la especialidad de matemáticas. Después de tantos cambios en su vida y una toma de decisiones que marcaría su futuro, se preparaba para lo que realmente deseaba: ser maestra. 


\subsection{Paso por la universidad}

En el momento en que Catuxa comienza su formación inicial como maestra, Magisterio se encontraba dentro de las enseñanzas universitarias reconocidas como Diplomatura, pero no se estudiaba en las Facultades, sino en las Escuelas de Magisterio.

Aunque pueda parecer algo sin importancia, en realidad no es así. Como señala Bernat (1982) en un trabajo de la época:

Las escuelas universitarias del profesorado de EGB están en la universidad, pero no son universidad. Desde hace una década jurídicamente forman parte de la universidad, pero ni están integradas efectivamente, ni son aceptadas por la misma y, lo que es más preocupante, un amplio sector de profesorado de estas escuelas no desea que esta integración se lleve hasta sus últimas consecuencias (p.18).

Catuxa nos cuenta que los profesores en aquella época eran, en general, meros transmisores de conocimientos, auspiciados por un modelo pedagógico caracterizado por una marcada distancia entre profesores y alumnos o por la ruptura entre la teoría y la práctica (Bernat, 1982). Sin embargo, también rememora vivencias positivas. Recuerda especialmente la asignatura de música que le costó mucho por su timidez, pero el docente era buenísimo y sacaba lo mejor del alumnado, o a la profesora de matemáticas hasta tercer año de carrera que hacía fácil lo difícil, poniendo de manifiesto tal y como afirma Gutiérrez (2014) la importancia del profesor como modelo. Este profesorado que trabajaba sobre la base de que después su alumnado sería también docente y "copiaría" para sus propias clases, era en palabras de Catuxa

$[\ldots]$ Como un oasis en medio del desierto [...]

[...] Mucho de lo que estudiamos y aprendimos, después lo apliqué en el aula, sobre todo lo de música. [...]

En este caso, Catuxa no sigue la regla de lo dicho por González y Pino (2014) quienes afirman que "lo asimilado a lo largo de la carrera no garantiza que los futuros docentes lo vayan a aplicar en las aulas" (p. 84), ya que ella si aplicó en su aula lo asimilado en la carrera.

\subsection{El acceso a la docencia}

Finaliza la carrera de Magisterio por matemáticas en el año 1977 después de tres años cursados. Como señala Molero (2000, p.76) los "estudios tenían una duración de tres años y al final expedían el título de Diplomado". En ese momento sintió total satisfacción y lo único que quería era impartir docencia:

[...] Me sentía feliz, pero al mismo tiempo preocupada. ¿Cuánto tardaría en poder ser una maestra de verdad? [...]

Por desgracia para Catuxa, este miedo se convierte en realidad. Durante varios años se presenta una y otra vez a la oposición de Educación Primaria por matemáticas, pero por mucho que aprobara, nunca consiguió plaza fija. Este examen lo repitió durante cuatro años seguidos hasta que finalmente cambió de 
especialidad. En el año 1982 se presentó por Preescolar, aprobó a la primera y consiguió la tan ansiada plaza de maestra:

[...] Pues mira, al final tuve que cambiar de especialidad y optar por presentarme a Educación Preescolar. No fue una decisión fácil en ese momento, y tuve muchas dudas que desparecieron en cuanto me incorporé al Magisterio [...]

En su incorporación a la docencia, Catuxa sigue la tónica predominante en la época señalada por Guerrero (1995):

De cada diez personas diplomadas como profesores de EGB, en la década de los ochenta, que hoy son enseñantes, sólo dos se han incorporado directamente. Cinco de ellas tuvieron que preparar oposiciones y las tres restantes buscaron trabajo o se dedicaron a trabajar en lo que les saliese o tuviesen ya (p.139).

Catuxa es, por tanto, una afortunada. En el tiempo que transcurre hasta que consigue destino fijo, cambió de colegios entre las provincias de A Coruña y Pontevedra. Estuvo en un colegio de Carballo, un pueblo de A Coruña, en el cual le costó un poco integrarse, ya que el alumnado tenía una serie de necesidades educativas especiales a las que ella no estaba acostumbrada, siendo esta situación objeto de reflexión. Relata que:

[...] Tenía una preocupación y un miedo enorme a que se hicieran algo (...). Ahí noté que no sabía cómo hacer, que me faltaba una parte importante en mi formación [...]

Los siguientes colegios en los que estuvo fueron escuelas unitarias, en zonas rurales también de la provincia de A Coruña. Finalmente aterriza en su tan querida Pontevedra, primero en un pueblecito a las afueras de la capital, y por último en su destino final dónde trabajó aproximadamente 25 años, en una pequeña aldea costera perteneciente a Cangas do Morrazo.

En este último colegio acepta la vivienda que le proporcionaba el estado. Aunque al principio iba y venía todos los días de Pontevedra a Cangas y de Cangas a Pontevedra, donde se encontraba el domicilio familiar y el de sus hermanos y hermanas. Finalmente optó por rehusar a esta práctica, ya que

[...] Al final, aunque era poca distancia, perdía mucho tiempo y acababa cansada. El quedarme permanentemente en Cangas me ayudó a centrarme más $[\ldots]$

\subsection{Los años de madurez.}

Catuxa se consolidó como maestra en el colegio en el cual consiguió plaza en el año 1989-1990, aproximadamente. En ese momento es cuando comienza el trato real con las familias, el centro y los alumnos, ya que con anterioridad prácticamente no tuvo tiempo a que hubiese un trato más estrecho.

Durante ese periodo, mantiene cercanas relaciones con el conjunto de la Comunidad Educativa, percibiendo como es tenida en cuenta y considerada, lo que genera una retroalimentación muy positiva: 
[...] Yo siempre me sentí muy valorada tanto por los compañeros como por los padres, esto hacía que mi autoestima estuviese siempre bien alta [...]

Esta autopercepción de Catuxa contrasta con la afirmación de García (1988), cuando señala que "la percepción personal que tienen los maestros de su baja consideración social genera consecuencias en diversos niveles: autoestima y equilibrio personal, reclutamiento del profesorado, absentismo y abandono, formación y calidad del sistema educativo en general" (p.253). A nuestra protagonista esto no le pasa, o no lo percibe así, y lo recuerda llena de orgullo y satisfacción.

Catuxa evoca mil y una experiencias buenas y malas con su alumnado, pero algunas las recuerda con más pasión que otras. El tener tantas experiencias con niños y niñas, la lleva a pensar en la estabilidad emocional, tanto de su alumnado como de ella misma, ya que esto les puede afectar en su aprendizaje:

[...] Influye mucho si estás de buenas o si tienes un problema o estás triste. Un maestro o maestra no puede desligar totalmente su vida profesional y personal. Aunque lo intentes con todas tus fuerzas, hay realmente muchas veces en las que no eres capaz. $Y$ tus alumnos lo perciben y lo sufren enormemente [...].

Esta reflexión no se la planteaba Catuxa en sus inicios. Pero además descubre que, en su caso, la dimensión profesional influye positivamente en la dimensión personal a nivel emocional, afirmando que

[...] mi trabajo no me influyó de forma negativa, sino todo lo contrario, me animaba y todo el trabajo llevado a cabo con el alumnado me reconfortaba mucho [...].

Catuxa, por tanto, formaría parte de ese colectivo de docentes que afirman estar satisfechos de ser profesores (Anaya y López, 2014). Y este comportamiento y actitud docentes tiene repercusiones para su alumnado, puesto que desde el nivel emocional "hay evidencia de que los conocimientos académicos se aprenden mejor si el alumnado está motivado, controla sus impulsos, tiene iniciativa, es responsable, etc. Es decir, si tiene competencias emocionales" (Bisquerra y Pérez, 2007, p.65). Y estas capacidades relacionadas con el mundo de las emociones, resultan de vital importancia para todas las esferas de la vida (Aguaded y Pantoja, 2015).

Cuenta que siempre fue muy comprensiva con los sucesos que iban transcurriendo, y que se iba adaptando sin problemas a los cambios en el aula, al ambiente familiar que podría influir en esta y al contexto en general como condicionante de la competencia emocional.

Puesto que Catuxa es una mujer, se podría pensar que dada la época en la que se inicia en la profesión docente, en algún momento de su vida laboral pudiera haberse sentido inferior a sus compañeros varones sólo por el hecho de ser mujer o por el tipo de carrera que escogió, tal y como se desprende de estudios recientes (Domínguez y Ospina, 2014). Pero tampoco es su caso, siempre se sintió muy arropada y en condiciones de igualdad con todo el elenco de profesorado del centro, sobre todo del último, ya que estuvo casi veinticinco años trabajando y siempre con varones como directores y como compañeros de profesión. 
Aparte de lo vivido día a día, lo compartido con el alumnado y el resto de la comunidad, hay ciertos factores internos que influyen mucho a nivel docente como son el cambio de leyes educativas y la introducción de nuevas metodologías que, en ocasiones, promueven y Catuxa vivió durante su ejercicio profesional la aprobación de tres leyes educativas. La primera bajo la que desarrolló su labor fue la Ley General de Educación (LGE) en el 1970 año, y de ella recuerda especialmente

[...] el elevado número de niños y niñas que había en el aula de Preescolar y su carácter de preparación para la enseñanza obligatoria que comenzaba con primero de EGB a los 6 años [...].

También rememora los comienzos de lo que a día de hoy se conoce como tutoría y acción tutorial. Con la LGE se reconoce por primera vez su importancia en el proceso educativo del alumnado, al mismo tiempo que se promueve al docente a la "colaboración con el resto de docentes y con las familias para determinar un proyecto educativo común y coherente" (Hernández, Viudez y Guerrero, 2015, p. 192)

Esto no supuso ningún problema para Catuxa puesto que, como ya se puso de manifiesto, su trabajo estuvo siempre orientado por la colaboración con la Comunidad Educativa y el trabajo en equipo con el resto de docentes. Como afirma nuestra protagonista:

[...] no tiene sentido "ir por libre". Todos tienen algo que decir, que aportar y todas esas aportaciones pueden y deben ser incorporadas a la propia actividad docente para intentar mejorarla [...].

Menos de 10 años trabajaría Catuxa bajo el paraguas de la LGE, puesto que en el año 1990 se aprueba la Ley de Ordenación General del Sistema Educativo (LOGSE), con la que convivirá la mayor parte de su carrera docente. Esta ley entra en su aula de forma tranquila y paulatina, y a pesar del incremento de responsabilidades que se le atribuyen al profesorado y a la inclusión de metodologías innovadoras que ponen el énfasis en la realización de aprendizajes significativos, no supone una ruptura drástica con lo que se estaba realizando hasta el momento, puesto que como ella señala:

[...] Yo siempre intenté que mis alumnos aprendieran significativamente. No sabía que se llamaba así lo que estaba haciendo, pero mi objetivo era que no solo acumularan conocimientos, sino que fuesen capaces de utilizarlos en otros contextos y darle un significado a lo aprendido [...].

Probablemente el mayor reto para Catuxa como docente tiene que ver con la inclusión de las Tecnologías de la Información y la Comunicación (TIC) y su utilización como recursos en el proceso de enseñanza-aprendizaje:

[...] los maestros no estábamos acostumbrados. Nuestra experiencia se reducía a la utilización del Vídeo y el Cassette, pero de ordenadores y cosas así, nada de nada. Esto generó sentimientos generalizados de incertidumbre, temor e incluso rechazo entre la mayor parte de los profesores [...]

En este contexto, la formación del profesorado se muestra como un elemento clave para superar este desafío. Así, se afirma que "además de necesaria, dado el carácter dinámico de la tecnología, es un elemento de mejora 
de la calidad institucional de los centros educativos" (Gisbert y Lázaro, 2015, p.124). Sin embargo, la percepción sobre la formación ofertada es que resulta insuficiente y no responde a las necesidades del profesorado:

[...] Salíamos casi como entrábamos, bueno un poco mejor, pero de cualquier forma no se nos ofrecía lo que necesitábamos. No creo que un maestro tenga que ser un especialista en cuestiones técnicas, sino que sobre todo tiene que conocer el qué y para qué de la utilización de esas tecnologías $[\ldots]$

Pese a esto, Catuxa considera que pueden ser una buena ayuda en el aula si sabe cómo hacerlo. Y comienza a incorporar las TIC en su modelo de enseñanza, lo que le supone un cambio muy grande. Desde sus vivencias en estos momentos de cambio, Catuxa considera que la educación del Siglo XXI debe asumir algunos retos, entre los que estarían el formar mejor al alumnado a nivel tecnológico, pero no sólo a ellos, sino también a los padres,

[...] Porque además del tiempo que pasa el niño en la escuela, también pasa tiempo en casa y este debería de estar bien enfocado, sobre todo por el abuso que, en ocasiones, se hace de la tecnología [...]

Dos años antes de su jubilación, se aprobará, en el año 2006, la Ley Orgánica de Educación (LOE). De su corta experiencia con ella no destaca nada en especial con respecto a su trabajo en el aula, siguió centrada en sus alumnos y en conseguir que aprendieran y disfrutaran.

Para finalizar, señalar que Catuxa cree firmemente que la decisión de estudiar Magisterio fue la más acertada y si volviera atrás no cambiaría esta decisión, ya que:

[...] Ser maestra fue lo que me hizo ser como soy. Y, en general, estoy muy satisfecha y contenta [...].

\section{CONCLUSIONES}

El objetivo principal de este estudio consistía en comprender como se crea la identidad docente, y la influencia que ejerce la vida privada, la laboral y las reformas educativas en la creación de la misma. Como objetivos específicos, se habían propuesto dos: dar a conocer la historia de vida de una docente de Educación Infantil, e identificar los elementos más significativos en la construcción de la identidad docente.

Los resultados presentados en el apartado anterior suponen una línea cronológica en la que Catuxa va desvelando aquellos aspectos más significativos, desde su punto de vista, en lo que respecta a su trayectoria personal y profesional. La contextualización temporal y espacial, así como el diálogo que se establece con la literatura sobre el tema (Goodson, 2004), nos permite ofrecer la historia de vida de nuestra protagonista, alcanzándose así el primero de los objetivos propuestos.

En lo que respecta al segundo de ellos, desde el conocimiento de historia de vida de Catuxa se observa que la creación de su identidad docente está vinculada a todo lo que le rodea, y que en mayor o menor medida todas sus 
vivencias y experiencias fueron ejerciendo influencia en su toma de decisiones y en su labor docente.

Tomando como referencia las investigaciones de Day et al. (2006) y Day (2011), quienes identifican tres puntos de influencia (sociocultural-político, lugar de trabajo o influencias sociales localizadas, e influencias personales) en la creación de la identidad docente, se pueden establecer las siguientes conclusiones.

A nivel sociocultural-político, se constata como a Catuxa las personas que más le marcaron su futura identidad como docente fueron precisamente sus maestras y maestros. En un principio, como ella cuenta, le marcó su profesora de la escuela unitaria por su buen carácter, y después algunos profesores de la universidad cuyas enseñanzas aplicaría en el futuro en su aula de Educación Infantil. Más adelante, los cambios legislativos en educación no supondrán para ella un problema, sino una ocasión de avanzar.

En segundo lugar, estaría el lugar de trabajo o las influencias sociales localizadas. Catuxa siempre se sintió en el colegio como una más, esto hizo que si tuviese que cambiar en algo, este cambio fuera siempre para bien, con una finalidad de mejora. Prácticamente no tiene malos recuerdos, sino que reconoce que la faceta profesional le ayudó en la personal, la motivó y la hizo seguir adelante.

Por último, con respecto a las influencias personales, podemos decir que en su familia siempre la apoyaron. Especial mención realiza con relación a su padre, destacando el respaldo y sostén que le proporcionó en una época, los años 70, en los que no estaba demasiado bien visto que la mujer trabajase o estudiase. Su padre se sintió muy orgulloso y la apoyó siempre, dándole esa fuerza que a lo mejor ella necesitaba para poder creer en sí misma.

Finalmente agradecer la generosidad de Catuxa, porque aceptar participar en esta investigación y ofrecernos su voz, puede posibilitar que futuros docentes vean la profesión de maestro con otros ojos, como ella la ve:

[...] Simplemente, maravillosa [...].

\section{DISCUSIÓN}

La mayor parte de las investigaciones sobre profesionalización docente se enmarcan en una metodología positivista que pretende obtener unos resultados y unas conclusiones universales (Sancho y Martínez, 2014), olvidando que lo que la persona es o siente es inseparable del ejercicio profesional. La realización de este estudio ha permitido profundizar en el proceso de cómo se llega a ser una maestra, desde un enfoque cualitativo que parte del reconocimiento del carácter contextual del conocimiento y que nos permite comprender mejor lo que "significa ser un profesor que se esfuerza por ser efectivo en una política cambiante, lugar de trabajo y contextos personales" (Day, 2011, p.47), lo cual sin duda es una aportación importante al campo de la formación del profesorado.

De los resultados y conclusiones presentadas se deriva información que concuerda con los alcanzados en otros estudios previos en relación con nuestro objeto de estudio. En primer lugar, nuestra protagonista interpreta y reinterpreta 
su identidad docente a partir de las experiencias vividas en el día a día (Beijaard et al., 2004, Correa et al., 2015, Day et al., 2006). Se constata también la influencia de las experiencias discentes y docentes como elemento clave para la comprensión de las actitudes y comportamientos futuros (Bolivar, 2014, Hargreaves, 2005, Zeichner y Gore, 1990), así como el compromiso emocional con su trabajo (Day, 2011), comprobándose como "la cara personal y emocional del cambio educativo ocupa un lugar central en el ejercicio profesional" (Bolivar, 2014, p.723).

Sin embargo, es necesario hacer mención a una serie de limitaciones que presenta y que sería importante subsanar en el futuro. En primer lugar, estaría el tratarse de un caso único, por lo que se muestra una sola historia de vida. A pesar de que esta opción está presente en la literatura sobre el tema, no cabe duda de que no aporta la misma riqueza que casos múltiples que permitan hacer análisis entrecruzados y realizar comparativas entre los factores de influencia de cada uno de los casos. Como afirma Hargreaves (2005), la identidad profesional docente presenta rasgos comunes a todos los miembros de la profesión, al mismo tiempo que es individual en función de la historia singular de cada uno y de sus características personales. En estos momentos se está trabajando con otras historias de vida de manera que, en un futuro próximo, se podrán ofrecer resultados más completos que permitan vislumbrar con mayor claridad puntos fuertes y puntos débiles que posibiliten el ofrecer líneas de trabajo para los responsables de la formación de profesores.

Por otra parte, la limitación de espacio del documento ha obligado a una selección de la información obtenida, por lo que este estudio solo es un extracto de la voz de Catuxa. Es posible que hayan quedado en el tintero vivencias importantes que a ella le hubiera gustado ver aquí reflejadas y que hubieran ayudado a comprender mejor el proceso de construcción de su identidad profesional..

\section{REFERENCIAS}

Aguaded Gómez, M.C. y Pantoja Chaves, M.J. (2015). Innovar desde un proyecto educativo de inteligencia emocional en primaria e infantil. Tendencias Pedagógicas, 26, 69-88. DOI: http://dx.doi.org/10.15366/tp2015.26

Anaya, D. y López, E. (2014). Satisfacción laboral del profesorado en 2012-13 y comparación con los resultados de 2003-04. Un estudio de ámbito nacional. Revista de Educación, 365, 96-121. DOI: http://dx.doi.org/10.4438/1988592X-RE-2014-365-266

Beijaard, D. Meijer, P.C. y Verloop, N. (2004). Reconsidering research on teacher professional identity. Teaching and Teacher Education, 20, 107-128. https://doi.org/10.1016/j.tate.2003.07.001

Bernat, A. (1982). Bases para un currículo de formación de profesores de E.G.B. Revista de educación, 269, 17-41. Recuperado de http://www.mecd.gob.es/dctm/revista-deeducacion/articulosre269/re2690213059.pdf?documentld=0901e72b813cd $\underline{44 \mathrm{~b}}$ 
Bilbao, B; Pérez, K y Ezkurdia, G (2014). La Investigación biográfica en la formación inicial de magisterio: Las historias de vida como temática del trabajo de fin de grado de Educación Infantil y Primaria. Tendencias pedagógicas, 24, 85-97. Recuperado de file:///C:/Users/usuario/Downloads/Dialnet-

LalnvestigacionBiograficaEnLaFormacionlnicialDeMag5236961\%20(2).pdf

Bisquerra, R. y Pérez, N. (2007). Las competencias emocionales. Educación XX1, 10, 61-82. DOI: https://doi.org/10.5944/educxx1.1.10.297

Bolivar, A. (2007). Formacion inicial del profesorado de secundaria y su identidad profesional. Estudios sobre la Educacion, 12, 13-30, Recuperado de http://hdl.handle.net/10171/8987

Bolívar, A. (2014). Las historias de vida del profesorado: voces y contextos. Revista mexicana de investigación educativa, 19(62), 711-734. Recuperado http://www.scielo.org.mx/scielo.php?script=sci arttext\&pid=S1405$66662014000300004 \& \operatorname{lng}=\mathrm{es} \& \ln \mathrm{n}=\mathrm{es}$

Bretones, E., Solé, J., Alberich, N. y Ros, P. (2014). Historias de vida y educación social: una experiencia de investigación y formación. Tendencias Pedagógicas, 24, 71-84. Recuperado de https://revistas.uam.es/tendenciaspedagogicas/article/view/2093/2191

Caballero, K. y Bolívar A. (2015). El profesorado universitario como docente: hacia una identidad profesional que integre docencia e investigación. REDU - Revista de Docencia Universitaria, 13(1), 57-77. Recuperado de http://redu.net/redu/index.php/REDU/article/view/900/pdf

Calderón, I. (2014). Sin suerte pero guerrero hasta la muerte: pobreza y fracaso escolar en una historia de vida. Revista de Educación, 363, 184-209. DOI: http://dx.doi.org/10.4438/1988-592X-RE-2012-363-177

Cohen, L. y Manion, L. (1990). Métodos de investigación educativa. Madrid: La Muralla.

Cook, T.D. y Reichardt, CH.S. (1986). Métodos cualitativos y cuantitativos en investigación educativa. Madrid: Morata.

Correa, J.M, Fernández, L., Gutiérrez-Cabello, A., Losada, D. y Ochoa-Aizpurua, B. (2015). Formación del Profesorado, Tecnología Educativa e Identidad Docente Digital. RELATEC. Revista Latinoamericana de Tecnología Educativa, 14(1), 45-56. DOI: 10.17398/1695-288X.14.1.45

Correa, J.M. (2014). Empezar a trabajar en la educacion infantil: las condiciones de acceso a la docencia en los relatos biográficos de las maestras principiantes Tendencias Pedagógicas, 24, 41-53. Recuperado de https://revistas.uam.es/tendenciaspedagogicas/article/view/2091/2189

Correa, J.M. y Aberasturi, E. (2014). Las historias de vida y la educación: introducción al monográfico. Tendencias pedagógicas, 24, 6-8. Recuperado de https://revistas.uam.es/tendenciaspedagogicas/article/view/2088/2186 
Cortés, P., Leite, A.E. y Rivas, J.I. (2014). Un enfoque narrativo de la identidad profesional en profesorado novel. Tendencias Pedagógicas, 24, 199-214. Recuperado https://revistas.uam.es/tendenciaspedagogicas/article/view/2101

Creus, A.S. (2010). Narrar experiencias, construir historias: (Re)visitando a Lara. Comunicación presentada en las I Jornadas de Historias de Vida en Educación, Barcelona, 10-11 de junio. Recuperado de: http://som.esbrina.eu/jornadeshistoria/docs/AMALIA CREUS.pdf

Day, C. (2007). Pasión por enseñar. La identidad personal y profesional del docente y sus valores, Madrid: Narcea.

Day, C. (2011). Uncertain Professional Identities: Managing the Emotional Contexts of Teaching. En: Day, C., Chi-Kin Lee, J. (Eds.), New Understandings of Teacher's Work: Emotions and Educational Change (pp. 45-64). Dordrecht: Springer. https://doi.org/10.1007/978-94-007-0545-6 4

Day, C., Stobart, G., Sammons, P., Kington, A., Gu, Q., Semees, R., Mujtaba, T. (2006). Variations in teachers' work, lives and effectiveness. Dfes Research Report 743. London: HMSO.

Domínguez, M.E. y Ospina, S. (2014). Identidad docente en autobiografías de tres generaciones de profesorado universitario en Colombia. Katharsis, 17, 65-94. Recuperado de: file:///C:/Users/usuario/Downloads/681-2691-1PB.pdf

Fernández, M. (1995). Ciclos en la vida profesional de los profesores. Revista de Educación, 306, 153-203.

García, E. (1988). Condición social y feminización del profesorado de educación básica. Revista de Educación, 285, 249-266.

Gisbert Cervera, M. y Lázaro Cantabrana, J.L. (2015). La formación permanente en competencia digital docente y la mejora de la calidad del centro educativo desde la perspectiva de los docentes: un estudio de caso. New approaches in educational research, 4 (2), 124-131. Recuperado de http://naerjournal.ua.es/article/view/v4n2-7

González, M. y Pino, M. (2014). Aproximación a las representaciones y creencias del alumnado de Magisterio sobre los estilos de enseñanza. Educación XX1, 17 (1), 83-110. DOI: https://doi.org/10.5944/educxx1.17.1.10706

Goodson, I.F. (2004) (coord.), Historias de vida del profesorado, Barcelona, Octaedro

Guerrero, A. (1995). La construcción social del magisterio: Orígenes sociales, trayectoria educativa y motivaciones profesionales. Revista de Educación, $306,127-151$.

Gutiérrez, L. (2014). La investigación narrativa en el Practicum de Magisterio a través de micro-relatos docentes: el relato de Montse. Tendencias Pedagógicas, 24, 23-40. Recuperado de https://revistas.uam.es/tendenciaspedagogicas/article/view/2090/2188

Hargreaves, A. (2005). Profesorado, cultura y posmodernidad. Cambian los tiempos, cambia el profesorado. Madrid: Morata 
Hernández, F. y Aberasturi, E. (2014). Las historias de vida como alternativa para visibilizar los relatos y experiencias silenciadas de la educación. Tendencias Pedagógicas, 24, 133-144. Recuperado de https://revistas.uam.es/tendenciaspedagogicas/article/view/2097/2195

Hernández, M.A., Viudez, N. y Guerrero, C. (2015). Percepción de las familias sobre las tutorías en la etapa de Educación Infantil. ENSAYOS, 30 (2). Recuperado de file:///C:/Users/usuario/Downloads/911-3944-1-PB.pdf

King, N. y Horrocks, C. (2010). Interviews in Qualitative Research. Londres: Sage.

Macuch, R. y Leite, C. (2014). Análisis de una narrativa autobiográfica profesional en la enseñanza superior. Tendencias Pedagógicas, 24, 145164.

Recuperado

de https://revistas.uam.es/tendenciaspedagogicas/article/view/2098/2196

Matus, L.G. (2013). La construcción de una identidad docente, ¿Un desafío para la política educativa? Exitus, 3(1), 75-87.

Molero, A. (2000). La formación del maestro español, un debate histórico permanente. Revista de Educación, núm. extraordinario, 59-81.

Monereo, C. y Domínguez, C. (2014). La identidad docente de los profesores universitarios competentes. Educación $X X 1$, 17(2), 83-104. DOI: 10.5944/educxx1.17.2.11480 https://doi.org/10.5944/educxx1.17.2.11480

Neiva, M., Lopes, A. y Pereira, F. (2014). Potencialidades da investigação narrativa na construção de uma investigação. Tendencias pedagógicas, 24, 165-184. Recuperado de https://revistas.uam.es/tendenciaspedagogicas/article/view/2099/2197

Pineau, G. (2004). Temporalidades na formação. São Paulo: Triom.

Piqué, B. y Forés, A. (2015). Una invitación a narrarse para educar. Historia de vida y universidad. Tendencias Pedagógicas, 25, 247-260. DOI: http://dx.doi.org/10.15366/tp2015.25. https://doi.org/10.15366/tp2015.25

Popkewitz, Th. S. (1990). Formación del profesorado. Tradición. Teoría. Práctica. Valencia: Universitat de València.

Porto, A.S. (2003). O maxisterio pontevedrés na II República, Guerra Civil e Franquismo. Ponteareas-Pontevedra: Alén Miño, S.L.

Pujadas, J.J. (2002). El método biográfico: El uso de las historias de vida en ciencias sociales. ( $2^{\mathrm{a}}$ ed.) Madrid: Centro de Investigaciones Sociológicas.

Román, J.M. y Cano, R. (2008). La formación de maestros en España (18382008). Necesidades sociales, competencias y planes de estudio. Educación $\quad X X 1, \quad 11, \quad 73-101 . \quad$ DOI: http://dx.doi.org/10.5944/educxx1.11.0.310 https://doi.org/10.5944/educxx1.11.0.310

Sánchez, E. (2003). La vocación entre los aspirantes a maestro. Educación XX1, 6, 203-222. DOI: $\quad$ http://dx.doi.org/10.5944/educxx1.6.0.357 https://doi.org/10.5944/educxx1.6.0.357

Sancho, J.M. y Martínez, S. (2014). La importancia de las relaciones investigador-investigado. Tendencias pedagógicas, 24, 225-240. 
Recuperado

de

https://revistas.uam.es/tendenciaspedagogicas/article/view/2103/2201

Schön, D. (1998). El profesional reflexivo. Cómo piensan los profesionales cuando actúan. Barcelona, Paidós Ibérica.

Serret-Segura, A., Martí-Puig, M. y Corbatón, R. (2016). Las historias de vida en la formación de maestros de educación infantil. Revista Iberoamericana de Educación, 71, 217-228. Recuperado de file:///C:/Users/usuario/Downloads/rie71a10\%20(3).pdf

Thomas, L. y Soares, R.E. (2015). O caráter pedagógico das narrativas biográficas no contexto da abordagem de ensino centrada no estudante. Tendencias Pedagógicas, 25, 261-277. DOI: http://dx.doi.org/10.15366/tp2015.25. https://doi.org/10.15366/tp2015.25

Valliant, D. (2007) “La identidad docente”, I Congreso Internacional "Nuevas Tendencias en la Formación Permanente del Profesorado", GTD-PREAL ORT, Barcelona, 5, 6 y 7 septiembre 2007. Recuperado de: http://www.scribd.com/doc/2030599/La-identidaddocente

Zeichner, K. y Gore, J. (1990). Teacher Socialization. En R. Houston (ed), Handbook on Research on Teacher Education (pp. 329-348). New York, USA: Macmillan. 